\title{
Researchers' perspectives on open access scholarly communication in Tanzanian public universities
}

\author{
F.W. Dulle \\ Department of Information Science, University of South Africa, Pretoria, South Africa \\ nzengamshe@yahoo.com
}

M.K. Minishi-Majanja

Department of Information Science, University of South Africa, Pretoria, South Africa

majanmk@unisa.ac.za

This research explored the awareness, usage and perspectives of Tanzanian researchers on open access as a mode of scholarly communication. A survey questionnaire targeted 544 respondents selected through stratified random sampling from a population of 1088 university researchers of the six public universities in Tanzania. With a response rate of $73 \%$, the data were analysed using the Statistical Package for Social Sciences. The study reveals that the majority of the researchers were aware of and were positive towards open access. Findings further indicate that the majority of researchers in Tanzanian public universities used open access outlets more to access scholarly content than to disseminate their own research findings. It seems that most of these researchers would support open access publishing more if issues of recognition, quality and ownership were resolved. Thus many of them supported the idea of establishing institutional repositories at their respective universities as a way of improving the dissemination of local content. The study recommends that public universities and other research institutions in the country should consider establishing institutional repositories, with appropriate quality assurance measures, to improve the dissemination of research output emanating from these institutions.

Key words: Institutional repositories, open access publishing, public universities, scholarly communication, Tanzania

Received 27 September 2009

\section{Contents}

1. Introduction

1.1 Developments and frustrations of scholarly communication

1.2 Open access concept

1.3 The problem

2. Research methodology

3. Presentation and discussion of the research findings

3.1 Profile of the respondents

3.2 Open access awareness

3.3 Open access usage

3.4 Researchers' general perspectives about open access

3.5 Challenges for Open Access scholarly communication adoption

4. Conclusion and recommendations

5. Acknowledgement

6. References

\section{Introduction}

Scholarly communication is a broad term reflecting various processes through which scholars exchange information with each other in the course of knowledge creation. The 'traditional' system of scholarly communication is said to have originated as an exchange of letters and lectures among scattered peers until scholarly print journals came into existence (De Beer 2005; Swan 2007). According to De Beer (2005:14), the first two scholarly journals, namely 'the Philosophical Transactions of the Royal Society of London in England' and 'the journal des scavans in France', were launched in 1665. Since the establishment of the first scholarly 
journals, scholarly communication has evolved, often stimulated by economic and technological changes (Moller 2006; Swan 2007; Thorin 2003; Yiotis 2005) but also by the needs of important stakeholders such as the researchers, publishers and end-users of research findings. From the first journal, for instance, scholarly publishing was dominated by the scholarly societies until after World War II when commercial publishers joined the industry owing to scholarly societies' failure to cope with the rapid increase of research output emanating from the universities (Yiotis 2005). Unlike scholarly societies that had no interest in making profits through journal sales, the commercial publishers utilised their control of the scholarly publishing industry to raise the journal prices. Eventually they have become unaffordable to the libraries and other institutions serving the scholarly community (Alemu 2009; Moller 2006; Thorin 2003; Yiotis 2005). In addition, there has been a rapid increase of scholarly output as the higher education sector has grown worldwide. This increase in scholarly output, coupled with inflated journal prices, has resulted in it becoming difficult even for libraries in rich countries to subscribe to every journal that is required by their clients. Worse still, scholars from the developing countries have been severely affected in terms of accessibility to scholarly content and literature because widespread poverty in these countries makes it impossible to keep up with escalating prices (Bjork, Roos and Lauri 2009; Habib 2009).

\subsection{Developments and frustrations of scholarly communication}

Meanwhile, developments in information and communication technology (ICT) have also contributed to the evolution of scholarly communication by greatly changing the documentation format and dissemination of scholarly content, among other aspects. ICT developments have dramatically changed research practices in terms of scholarly communication by enhancing communication among scientists and access to information of all kinds, and by provision of a greater variety of publication and dissemination platforms (Moller 2006). According to Willinsky (2003), 75\% of journals are currently available online and among them more than 1000 peer-reviewed journals are said to be documented in digital format only. Publishers have adapted to the online publishing environment by changing the legal framework for accessibility from copyright law, which was prevalent to print format, to contract law for digital format publications (ALA 2003; Swan 2007), with significant impact on libraries and other end-users. Under the contract law, individual libraries or consortia sign contracts with publishers for online accessibility to bundles of journals at an agreed cost, usually for several years. In such an arrangement, even those journals that are not needed by a specific research community are paid for if they are part of the 'bundle'. In the real sense, this kind of arrangement tends to militate against the envisaged solution of making scholarly content available to the research community (Swan and Brown 2005) through ICTs. In many countries,

'Library budgets have continued to see only modest annual increases whilst publishers have negotiated three or five year deals with year on year increases in charges, tying the libraries into long-term commitments in cash. ...these big deals with the large publishers have resulted in very large proportion of a library's budget being committed in this way, leaving little over for other purchases' (Swan and Brown 2004: 5).

Under such circumstances, many libraries, especially in the developing countries, are unable to accept the contracts or, when they do, they run a great risk of violating the contract because the budgets for most developing countries' libraries are often too small and unpredictable for long-term commitments. Furthermore, their budget cycles are usually shorter than the commitment to three to five year deals. It is evident that most of the 'big deals' that had been signed in developing countries had only been possible when there were externally supported programmes (Chan 2004; Chege 2006; Kirsop and Chan 2005). Such deals are also deemed to be unsustainable once the external donation ends.

Another dimension to the issue of scholarly communication is the fact that the scholarly community is often exploited by the traditional publishing industry in the sense that research institutions pay three times to access scholarly information generated by them. In the first instance, the research institutions fund the research projects, secondly the same institutions pay salaries to academics or researchers who conduct research and carry out the peer review of the research outputs, all at no cost to the publishing industry. Thirdly, the research institutions then purchase the scientific publications containing the very same research outputs that they handed over to publishers free of charge (Comba and Vignocchi 2005; Lynch 2003). Another drawback of traditional scholarly publishing is the fact that a substantial amount of research output, especially grey literature that does not follow the normal publishing protocols, remains invisible to most of the scholarly community.

In response to the frustrating traditional scholarly communication system, supported by enabling technologies, the scholarly community has come up with an alternative scholarly publishing system aimed at wider distribution of scholarly content without the cost or other copyright restrictions to end-users (Bernius, Hanauske, Konig and Dugall 2009; Bjork 2004; Moller 2006; Yiotis 2005). The emerging scholarly communication model is known as open access (OA). 


\subsection{Open access concept}

The Berlin Declaration of Open Access (2003:2) defines open access as a new mode of scholarly communication through which

'the author(s) and right holder(s) of scholarly work grant(s) to all users a free, irrevocable, worldwide right of access to, and a license to copy, use, distribute, transmit, and display the work publicly and to make and distribute derivative works, in any digital medium for any responsible purpose, subject to proper attribution of authorship'.

According to this definition, a complete version of the work and all supplemental materials should have been deposited in at least one online repository, using the suitable technical standards to enable open access, unrestricted distribution and long-term archiving of such works and including the permission to use the work.

OA scholarly communication is achieved through two main channels: Open access journals (OAJs) for electronic refereed journals and self-archiving (Bailey 2006; Bjork et al. 2009; Chan and Costa 2005). Open access journals, also referred to as the 'Gold Road' to open access, are peer reviewed journals made available free of charge to the public through the Internet. Unlike the business publishing model, in open access publishing, the end-user is not charged to access journal articles. Instead, various funding strategies, such as direct author fees, institutional membership to sponsor all or part of author fees, funding agency payment of author fees and grants to open access publishers and institutional subsidies, are used to cover the costs for publication and distribution of OA content for free access by the end-user (Hirwade and Rajyalakshmi 2006).

Self-archiving, also known as the 'Green Road' to open access, is making articles freely available in digital form on the Internet by authors (Budapest Open Access Initiative 2002). This is achieved when authors make their research output available through their personal Web sites or through open access archives. Open access archives are electronic repositories that may include already published articles (post-prints), pre-published articles (pre-prints), theses and dissertations, manuals, teaching materials or other documents that authors or their institutions wish to make publicly available without financial or other access barriers (Bailey 2006; Bjork 2004; Lynch 2003). The Registry of Open Access Repositories (ROAR) and the Directory of Open Access Repositories (DOAR ) provide the list of open access compliant archives from disciplinary and institutional archives worldwide.

\subsection{The problem}

Despite the promising potential of open access to improve scholarly communication, this mode of publishing is not yet wide spread in developing countries when compared to developed countries (Moller 2006; Papin-Ramchan and Dawe 2006; Wang and Su 2006). According to the Directory of Open Access Repositories (DOAR 2009; 2010), for example, the whole of the African continent had 24 registered open access repositories by the end of July 2009. During the same period, repositories registered in DOAR from other continents were 77 for Australia, 167 for Asia, 404 for North America and 686 for Europe. Data obtained from the Directory of Open Access Journals (DOAJ) during the same period indicate that among 4171 registered journals in DOAJ, only 23 journals were identified as being published or hosted in African countries (DOAJ 2009; 2010). By the end of January 2010, the number of open access repositories from the African continent in DOAR had increased to 35, of which 23 were from South Africa. Similarly, during the same period, the number of open access journals from the African continent had increased to 26 of which the majority (19) were again published in South Africa. Among the open access repositories and OA journals, none of them were from Tanzania. These statistics further support the observations made in the previous studies regarding the low uptake of open access in developing countries as noted above.

In an effort to find out why open access uptake is low and slow in most developing countries, the authors of this article decided to explore the perspectives of researchers in Tanzanian public universities on open access. Researchers within universities in developing countries are usually the main producers of scientific research results and hence considered very important in fostering open access uptake in a country. In other words, academics and scientists should be the prime agents of the new scholarly communication mode. Through their publishing activities, they are expected to be in the forefront of using open access outlets, hence determining whether or not open access journals or open access repositories become widely acceptable (Fullard 2007). Results reported in this article are part of a larger study entitled 'An analysis of open access scholarly communication in Tanzanian public universities', whose objectives were to: (a) investigate the general awareness and open access usage; (b) find out factors that facilitate researchers' adoption of open access; (c) determine factors that hinder researchers' adoption of open access; (d) find out researchers' perspectives on open access; and (e) suggest strategies to resolve the hindrances to open access adoption. This article focuses on the first, fourth and fifth objectives of this main study. 


\section{Research methodology}

The study was conducted at six out of eight Tanzanian public universities. The universities involved in the study were: Ardhi University (ARU), Muhimbili University of Health and Allied Sciences (MUHAS), Mzumbe University (MU), Open University of Tanzania (OUT), Sokoine University of Agriculture (SUA) and the University of Dar es Salaam (UDSM). The main criteria for selection of the participating universities were that they offered postgraduate training, had Internet connectivity and had existed at least 10 years as higher learning institutions. The other two public universities (the State University of Zanzibar and the University of Dodoma) did not meet the selection criteria. The reasoning behind the selection criteria was that existence as higher learning institutions for at least 10 years and running postgraduate programmes implied a comparatively well established research infrastructure and generation of research output. By meeting such conditions, the selected institutions were deemed to more likely benefit from OA initiatives than the other two institutions that were excluded in the study.

The study targeted researchers from the ranks of lecturers to professors. Junior researchers (tutorial assistants and assistant lecturers) were not included in the study on the assumption that they were not experienced in research and scholarly communication and therefore their contribution to this kind of study would be minimal. Semi-structured questionnaires were distributed to the sample population of 544 respondents who were selected through stratified random sampling from a population of 1088 researchers. Stratified random sampling was necessary to ensure the representation of the respondents on the basis of their gender, rank and research discipline (Neuman 2007). Of the $405(74,5 \%)$ returned questionnaires, $398(73,2 \%)$ were found usable for analysis while seven were discarded as incomplete.

Table 1

Questionnaire distribution and response rate $(\mathrm{N}=544)$

\begin{tabular}{|l|c|c|c|}
\hline Ins titution & Distributed copies of que stionnaires & Returned copies of completed ques tionnaire & Res ponse rate (\%) \\
\hline ARU & 27 & 21 & $\mathbf{7 8}$ \\
\hline MUHAS & 84 & 57 & $\mathbf{6 8}$ \\
\hline MU & 46 & $\mathbf{5 9}$ & $\mathbf{8 5}$ \\
\hline OUT & 40 & 100 & $\mathbf{8 1}$ \\
\hline SUA & 123 & 159 & $\mathbf{7 1}$ \\
\hline UDSM & 224 & 398 & $\mathbf{7 3}$ \\
\hline TOTAL & 544 & & \\
\hline
\end{tabular}

Table 1 summarises the questionnaire distribution and the response rate. Mzumbe University had the lowest return rate of 59\% while the Open University of Tanzania had the highest response of 85\%. After data collection, editing (by checking and adjusting for errors, omissions, and legibility) was done to ensure completeness, consistency and readability. Data were analysed using the Statistical Package for Social Sciences (SPSS) version 15. Content analysis was used to analyse data emerging from open-ended questions.

\section{Presentation and discussion of the research findings}

The study results are presented and discussed according to the three main objectives of focus in this article: investigate the general awareness and open access usage; find out researchers' perspectives on open access; and recommend strategies to enhance the adoption of open access in Tanzania.

\subsection{Profile of the respondents}

Out of the 398 respondents, $78 \%$ (310) were male and 22\% (88) female. Regarding the age groups, 18,6\% were aged between 31 and 40 years; 39,4\% between 41 and 50 years; 36,4\% between 51 and 60 years; and 4,5\% were above 60 years old, indicating that the majority of the respondents were aged between 41 and 50 years while those above 60 years formed the smallest group. The distribution of the respondents by rank for each institution is summarised in Table 2. 
Table 2

Distribution of respondents $(\mathrm{N}=398)$

\begin{tabular}{|c|c|c|c|c|c|c|c|}
\hline \multirow[t]{2}{*}{ Rank } & \multicolumn{6}{|c|}{ Institution } & \multirow[t]{2}{*}{ Total (\%) } \\
\hline & $A R U$ & MUHAS & $\mathrm{MU}$ & OUT & SUA & UDSM & \\
\hline Lecturer & 10 & 20 & 17 & 24 & 30 & 83 & $184(46,2)$ \\
\hline Seniorlecturer & 9 & 23 & 8 & 7 & 25 & 27 & $99(24,9)$ \\
\hline Professor & 2 & 14 & 2 & 3 & 45 & 49 & $115(28,9)$ \\
\hline Tota I (\%) & $21(5,3)$ & $57(14,3)$ & $27(6,9)$ & $34(8,5)$ & $100(\mathbf{2 5}, \mathbf{1})$ & $159(39,9)$ & $398(100)$ \\
\hline
\end{tabular}

It can be noted from Table 2 that the $46,2 \%$ of the respondents were lecturers, $28,9 \%$ were professors, and $24,9 \%$ senior lecturers. In terms of the highest academic qualifications attained, $75,1 \%$ were found to be holders of doctoral degrees while the remaining $24,9 \%$ had masters' degrees.

Researchers' disciplines were broadly classified into two categories: natural sciences and social sciences. The distribution of researchers by discipline was 159 (41,4\%) for social sciences and 225 (58,6\%) for natural sciences. Fourteen respondents did not indicate their research disciplines; hence they are not included in this calculation.

\subsection{Open access awareness}

The respondents were asked whether or not they had heard about open access before their participation in this survey and if so how they had become informed about it. Among the 392 researchers who responded to this question, the majority (72,1\%) had heard about open access while $26,4 \%$ had not. Of the respondents, $42 \%$ learnt of open access from their colleagues, $19,3 \%$ learnt of it through publishers' promotion and $18,8 \%$ learnt of it by following the Internet debate, while the remaining $29,9 \%$ learnt of open access at workshops/conferences, through library promotion, by chance while surfing the Internet, and during postgraduate studies abroad. Several other studies acknowledge university/library Web sites, contact from institutional repository staff members, publicity through campus newspapers, results of a Web search engine/Internet, direct publicity from publishers, word of mouth from associates and participation in an initial meetings of institutional repositories as ways through which respondents are exposed to open access (Kim 2006; Moller 2006; Pelizzari 2003; Swan and Brown 2005). These results imply that advocates of open access can use a combination of methods in promoting this mode of scholarly publishing to researchers.

\subsection{Open access usage}

Open access usage was investigated to determine the extent to which researchers accessed and disseminated scholarly content through the open access mode of scholarly communication. Tables 3 and 4 present results on researchers' usage of open access.

Table 3

Open access usage by the respondents by gender

\begin{tabular}{|c|c|c|c|c|}
\hline \multirow[t]{3}{*}{ Gender } & \multicolumn{4}{|c|}{ Open access usage (number and percentage) } \\
\hline & \multicolumn{2}{|c|}{ Scholarly content access $(\mathrm{N}=398)$} & \multicolumn{2}{|c|}{ Scholarly content dissemination ( $N=393$ ) } \\
\hline & Yes & No & Yes & No \\
\hline Male & $197(79,4)$ & $113(75,3)$ & $61(82,4)$ & $244(76,5)$ \\
\hline Female & $51(20,6)$ & $37(24,7)$ & $13(17,6)$ & $75(23,5)$ \\
\hline Total & $248(100)$ & $150(\mathbf{1 0 0})$ & $74(100)$ & 319 (100) \\
\hline
\end{tabular}


It can be noted from Table 3 that the majority $(62,3 \%)$ of the respondents claimed to have had access to open access materials while $37,7 \%$ claimed to have never accessed such content. Conversely, only $74(18,6 \%)$ respondents claimed to have published in such outlets. Table 3 further shows that of the 248 respondents who acknowledged having accessed open access content, $79,4 \%$ were males and $20,6 \%$ were females. This compares to $82,4 \%$ males and $17,6 \%$ females who indicated having disseminated their scholarly content through open access outlets.

Table 4

Usage of open access scholarly communication by discipline $(\mathrm{N}=398)$

\begin{tabular}{|c|c|c|c|c|}
\hline \multirow[t]{3}{*}{ Research discipline } & \multicolumn{4}{|c|}{ Open access usage (number and percentage) } \\
\hline & \multicolumn{2}{|c|}{ Scholarly content access ( $N=384)$} & \multicolumn{2}{|c|}{ Scholarly content dissemination $(\mathrm{N}=379)$} \\
\hline & Yes & No & Yes & No \\
\hline Biological sciences & $33(13,8)$ & $16(\mathbf{1 1}, \mathbf{1})$ & $10(13,7)$ & $37(12,1)$ \\
\hline Biomedical sciences & $62(25,8)$ & $14(9,7)$ & $36(49,3)$ & $39(12,7)$ \\
\hline Other applied sciences & $56(23,3)$ & $44(30,6)$ & $12(\mathbf{1 6 , 4 )}$ & $88(28,8)$ \\
\hline Social sciences & $89(37)$ & $70(\mathbf{4 8 , 6 )}$ & $15(20,5)$ & $142(46,4)$ \\
\hline Total & $240(100)$ & $144(100)$ & $73(100)$ & $306(100)$ \\
\hline
\end{tabular}

An analysis of Table 4 reveals that of the 240 respondents who acknowledged having accessed free scholarly content, 89 (37\%) were from the social sciences as compared to 151 (63\%) who were from the natural sciences. With respect to publishing in open access outlets, it can be noted from Table 4 that the researchers from the biomedical sciences were more involved in disseminating their research findings using open access than those from all other sub-research disciplines. It should be noted that the discrepancy in response totals between Tables 3 and 4 is a result of the fact that eight respondents among the 248 respondents (who indicated to have accessed open access content) did not provide their research disciplines and therefore could not be included in the calculation. Likewise, from the 74 who indicated to have published in open access outlets, one respondent did not indicate his/her research discipline and was hence excluded in the calculation. Nevertheless, the usage of open access scholarly content access by the respondents varied significantly $(p<0,01)$ among different research disciplines. Similarly, the dissemination of scholarly content through open access varied significantly $(p<0,001)$ in different research disciplines.

From the findings, it was evident that Tanzanian researchers predominantly used open access to access information as opposed to disseminating their scholarly content. The situation whereby researchers' publish less than they access content in open access outlets is not peculiar to public universities in Tanzania. Similar findings are reported by other open access studies done elsewhere (Gadd, Oppenheim and Probet 2003; Schroter and Tite 2006). A notable example is the study done by Gadd et al. (2003) where $57,8 \%$ of 456 respondents were reported to have submitted papers to open access journals in comparison to $88 \%$ who acknowledged to have accessed free content made available by other scholars. A survey by Deoghuria and Roy (2007) also established that out of 125 respondents, $80 \%$ used open access to access literature and $20 \%$ used open access for publishing their research output. Similar findings reported by Mann, Walter, Hess and Wigand (2008) indicate that despite $66 \%$ of the respondents claiming to use open access publication media at least once in their academic career, only $28 \%$ had actually published using the same media.

\subsection{Researchers' general perspectives about open access}

Researchers' general perspectives about open access were assessed by establishing their attitudes towards open access scholar communication as well as how they perceived the establishment of open access repositories at their respective institutions.

\subsubsection{Researchers' attitudes on open access}

The results of researchers' attitudes towards open access are presented in Table 5. 
Table 5

Researchers' attitudes towards open access $(\mathrm{N}=396)$

\begin{tabular}{|c|c|c|c|c|c|}
\hline \multirow[t]{2}{*}{ Attitude statem ent } & \multicolumn{5}{|c|}{ Ratings (fr eque ncy and perc entages) } \\
\hline & Strongly agree & Agree & Disagree & Strongly disagree & Don't know \\
\hline $\begin{array}{c}\text { Publishing in open access is a go od } \\
\text { idea }\end{array}$ & $166(41,9)$ & $180(45,5)$ & $17(4,3)$ & $7(\mathbf{1 , 8})$ & $26(6,6)$ \\
\hline $\begin{array}{c}\text { Publishing in ope } n \text { access out ets } \\
\text { would make my work more in te resting }\end{array}$ & $70(17,9)$ & $150(38,2)$ & $102(26)$ & $20(5,1)$ & $51(13)$ \\
\hline $\begin{array}{c}\text { Acce ssing and use of open access } \\
\text { materials is a go od idea }\end{array}$ & $116(29,4)$ & $203(51,4)$ & $36(9,1)$ & $5(1,3)$ & $49(11,9)$ \\
\hline $\begin{array}{l}\text { Open access content is beneficial to } \\
\text { the scholarly community }\end{array}$ & $147(47,3)$ & $168(42,6)$ & $25(6,3)$ & $5(1,3)$ & $49(12,4)$ \\
\hline $\begin{array}{c}\text { Publishing in open accessis easy for } \\
\text { me }\end{array}$ & $44(11,2)$ & $119(\mathbf{3 0 , 4 )}$ & $112(28, \mathbf{6})$ & $41(10,5)$ & $76(19,4)$ \\
\hline
\end{tabular}

It was revealed that the majority of the respondents were very positive as evidenced in all the provided attitude statements. The first four attitude statements were positively rated by more than $50 \%$ of the respondents, implying that they supported open access publishing. Researchers' positive attitude towards open access was also noted in individuals who provided general comments about open access. The following are some of the statements given:

- $\quad$ 'OA is very new to most academicians though it seems to be very good as far as accessibility to information is concerned'

- $\quad$ 'OA is something new and interesting - it should be promoted'

- $\quad$ 'Developing countries should accelerate the pace of establishing OA publishing in order to make their publications widely accessible'

- $\quad$ 'OA publications increase the visibility and impact of scientific findings from researchers to a wide audience especially in developing countries'

- $\quad$ 'Scholars in developing countries should be encouraged to publish in OA so that their findings reach more people.'

Some individuals accepted open access with caution as revealed in the following statement: 'Open access is good for information sharing but there is a need for a good mechanism to ensure quality control to avoid poor quality materials'. Only in the last statement did the majority of the respondents give negative responses towards open access. It is interesting to note that other similar studies also report that the majority support open access regardless of whether the scholars had published or not in such outlets (Hess, Wigang, Mann and Walter 2007; Kim 2006; Mann et al. 2008; SARUA 2008; Schroter and Tite 2005; Swan and Brown 2005). These results suggest that the introduction of open access in Tanzanian public universities should not be meeting with much resistance from the researchers and hence there must be other reasons for the slow uptake of open access usage.

\subsubsection{Researchers' perceptions on institutional open access repositories}

Before seeking researchers' views regarding their acceptance of open access repository establishment at their institutions, they were first required to comment on whether or not the dissemination of research output emanating from their respective institutions was a problem. A total of 392 respondents provided answers to this question. The majority $(83,1 \%)$ averred that the dissemination of research output at their respective universities was a problem as most of it is being documented as grey literature in print formats. Only 16,8\% did not consider it problematic to disseminate research output at their respective universities.

The respondents were then requested to indicate the importance that they attach to the establishment of institutional repositories as a strategy to improve the dissemination of research output at their universities. The majority, that is 384 ( $96,5 \%)$, considered the establishment of repositories important. These findings mirror other studies that indicate that most respondents endorse the establishment or were willing to contribute or submit in institutional repositories (Kim 2006; Lwoga 2006; Pelizzari 2003; Swan and Brown 2005; Xu 2005). Support of the establishment of institutional repositories by many respondents in this study was in harmony with their positive perceptions about open access as noted above.

The respondents were further asked to indicate the most preferred content for the institutional repositories. Table 6 presents the results of preferred institutional repository content as suggested by the respondents. 
Table 6

Preferred institutional repository content $(\mathrm{N}=398)$

\begin{tabular}{|c|c|c|}
\hline Preferred content & Frequency & 322 \\
\hline Conference papers & 320 & 80,9 \\
\hline Peer reviewed articles published in a journal & 314 & 70,4 \\
\hline Theses/dissertations & 244 & 78 '9 \\
\hline Teaching materials & 122 & 30,6 \\
\hline Non-peer reviewed articles published in a journal & 75 & 18,8 \\
\hline Articles awaiting peer review in a journal & \\
\hline
\end{tabular}

The most preferred repository content, in order of priority, were conference papers, peer reviewed articles in a journal, theses/dissertations and teaching materials. Non-peer reviewed articles were least preferred to be included in the repository. Research reports, consultancy reports and annual institutional reports (in order of priority) were among the additional publications highly ranked by the researchers for inclusion in the institutional repositories. The preferred repository content as suggested by the respondents collaborated with recommendations made by several previous studies (Lwoga 2006; Pickton 2005; Swan and Brown 2005; Van der Merwe and Kroeze 2008).

Furthermore, the researchers were required to suggest what they would consider as acceptable use of their materials if deposited in the repository. Table 7 summarises the results of acceptable use of the repository materials.

Table 7

Allowable use of materials in institutional repository $(\mathrm{N}=398)$

\begin{tabular}{|c|c|c|}
\hline Allowable institutional repository content use & Frequency & 290 \\
\hline Any use of deposited works so long it is properly acknowledged & 72,9 \\
\hline Individuals should register first before using deposited works & 207 & 92 \\
\hline Anybody should be allowed to comment/or add notes on deposited works & 23,4 \\
\hline
\end{tabular}

The majority of the respondents (72,9\%) would allow any use of their works deposited in the institutional repository as long as users provided proper acknowledgement. Many (52\%) of the respondents would only allow usage of their works upon users' registration. Only $23,4 \%$ would allow users to add comments or notes on their deposited works. The possibilities to view/display, print, save, copy and quote were also found to be the acceptable use of repository content by many respondents, as reported by Gadd et al. (2003) and Pelizzari (2003). The acceptance of any use of repository materials with an acknowledgement condition implies that many researchers were in agreement with the main principle of open access, namely the removal of barriers to scholarly content dissemination.

To find out how researchers valued the review of publications to ensure the integrity of scholarly communication, the respondents indicated the importance of reviewing publications (for publications without peer review) before being deposited in the institutional repository. Most respondents, 42,7\%, considered it very important, 43,5\% said it was important, 8,8\% claimed that it was either less important or least important while the remaining $5 \%$ had no comment. As to the composure of the review team, 30,7\% favoured a departmental research committee, 26,8\% preferred a faculty/institute/directorate committee, 19,1\% preferred a university-wide committee to do the review process, while the rest were divided between specialists in the field, external experts, selected reviewers or the university technical team. These findings suggest the need to pay attention to the review of publications before self-archiving in institutional repositories. The results from this study resemble observations made by Fullard (2007), Pelizzari (2003), Van der Merwe and Kroeze (2008), Wang and Su (2006) and Warlick and Voughan (2006). In all the referred studies, the peer review process is considered important so that open sources cannot be judged as holders of inferior content.

The respondents were also required to propose the most appropriate unit within their universities that they thought should manage the institutional repository once established. The findings were as follows: $244(61,3 \%)$ preferred the university library as the most appropriate unit for managing institutional repository, 78 (19,6\%) preferred the university-wide research coordination unit, 47 
$(11,8 \%)$ chose each faculty/institute/directorate while the remaining $29(7,3 \%)$ gave no opinion. Studies by Pelizzari (2003) and De Beer (2005) also established that many respondents prefer libraries as the most appropriate for the management of institutional repositories.

The preference for the library as the most appropriate unit for institutional repository management was motivated by several reasons including: repository management being the task of the library in other places; the library being well equipped in terms of ICT facilities and expertise; and the library having a mandate of information management for the university and therefore it should also manage the repository. Those who preferred the university-wide research unit argued that: such a unit usually also controls all research activities at the university and therefore it would be easy to track research output for inclusion in the repository; the university-wide unit is mandated with coordination and dissemination of research findings; the unit is representative of the whole university; and the unit is responsible for quality control of publications from the university and hence well positioned to manage the institutional repository. The preference for faculty/institute was motivated by the argument that it would make the review process less bureaucratic because both the people who form the review panel and the publications for review would be located at the same unit.

All in all, the general perspective of Tanzanian researchers towards open access, both as a content provider and a distribution of output, was found to be positive. This suggests that the poor uptake or low utilisation of open access outlets, especially for content distribution, must be a result of other challenges.

\subsection{Challenges for open access scholarly communication adoption}

Despite the general open access support by the majority of the researchers as noted above, several challenges should be addressed for effective exploitation of open access opportunities to improve scholarly communication in Tanzanian public universities. These challenges are briefly highlighted below.

\subsubsection{Researchers' self-efficacy, fears and misconceptions}

Several factors were identified as constraints challenging researchers' usage of open access systems. As shown in Table 8, most respondents (44\%) identified the lack of adequate skills for open access publishing as a major contributing factor militating against them.

Table 8

Reasons for not publishing in open access outlets by researchers $(\mathrm{N}=288)$

\begin{tabular}{|c|c|c|c|c|c|}
\hline Reasons & \multicolumn{5}{|c|}{ Ratings (number and percentage) } \\
\hline & Strongly agree & Agree & Disagree & Strongly disagree & Don't know \\
\hline Lack adequate skills to publish in open access outlets & $106(38,8)$ & $69(24)$ & $45(15,6)$ & $25(8,7)$ & $43(\mathbf{1 4 , 9 )}$ \\
\hline $\begin{array}{l}\text { Long-term availability of open access publications is not } \\
\text { guaranteed }\end{array}$ & $29(10,1)$ & $73(25,3)$ & $46(16)$ & $22(7,6)$ & $118(41)$ \\
\hline $\begin{array}{l}\text { Open access publications are of low quality as compared to } \\
\text { subscribed ones }\end{array}$ & $39(13,6)$ & $80(41,6)$ & $55(19,2)$ & $31(\mathbf{1 0 , 8 )}$ & $81(28,3)$ \\
\hline $\begin{array}{c}\text { Open access publications are likely to be misused or } \\
\text { plagiarised }\end{array}$ & $53(\mathbf{1 8 , 5 )}$ & $93(\mathbf{3 2}, \mathbf{5})$ & $37(12,9)$ & $21(7,3)$ & $82(28,7)$ \\
\hline $\begin{array}{l}\text { Open access publishing is not compatible with existing } \\
\text { scholarly communication practice }\end{array}$ & $24(8,3)$ & $57(19,7)$ & $74(25,5)$ & $20(6,9)$ & $114(39,4)$ \\
\hline
\end{tabular}

The other reasons that were highly ranked included: the likelihood that open access publications would be misused or plagiarised (51\%); the general perception that open access publications were of low quality compared to traditional publications (55,2\%); and researchers' worry about the long-term availability of open access publications (35,4\%). These findings corroborate previous studies that found that uncertainties over later publishing of open access articles elsewhere, violation of publishers' copyrights, and plagiarism of open access papers are among the cited respondents' deterrents for their contribution to institutional repositories (Fang and Zhu 2006; Foster and Gibbons 2005; Hirwade and Rajyalakshmi 2005; Kim 2006; Pickton 2005; Ware 2004; Xu 2005). It is necessary to address these challenges to foster the adoption of open access in Tanzania and other institutions elsewhere with a similar research environment. 


\subsubsection{ICT infrastructure}

Slow Internet speed was reported by the researchers as the major reason for low utilisation of open access outlets in accessing and disseminating scholarly content. The main cause for the slow connectivity was probably due to low bandwidth available at all the six public universities. Through interviews with policy makers and further follow-up consultations with officials of the university computer services, it was revealed that the university of Dar es Salaam had an Internet speed of 12,5 mega bits per second (mbps) downlink and 1,5 mbps uplink; Muhimbili University of Health and Allied Sciences had 1,024 mbps downlink and 0,512 uplink; Sokoine University of Agriculture had 2,048 mbps downlink (shared 1:8) and 0,256 uplink; Ardhi University had 1,2 mbps downlink and 0,2 mbps uplink; Mzumbe University had 1,0 mbps downlink and 1,0 mbps uplink; and the Open University of Tanzania had 0,512 mbps downlink/uplink. Although the University of Dar es Salaam seemed to have the highest speed, it also had the highest user population when compared to the other universities. Hence the high number of users rendered the relatively higher bandwidth inadequate.

It would therefore be necessary for all the universities in the study to improve their connectivity to enable the researchers to benefit from open access opportunities. Proper bandwidth management would be equally important to optimise the already limited connectivity. Hopefully, the problem of slow connectivity would be solved once these universities get connected to the high speed submarine fibre optic cable that was launched by President Jakaya Kikwete of the United Republic of Tanzania (Shame 2009).

\subsubsection{Inadequate researchers' information search and publishing skills}

The electronic information environment has posed challenges to researchers with regard to their ability in accessing and disseminating scholarly content. This is due to the fact that the 'developing web technologies relating to information access and publishing [are] becoming more sophisticated' (Harle, 2009:15), such that there is a need to upgrade the technical skills of the existing staff if they are to cope with the new and dynamic technological developments. However, in this study, only 20 (5\%) respondents cited their inadequate skills to access online information and 175 (44\%) respondents cited their inadequate skills to publish on online sites as the main reason for non-use of open access opportunities. Even though only a few researchers indicated this problem, it may still be necessary for libraries and university computing centres to actively impart these skills to researchers within their respective universities.

\subsubsection{Lack of open access supportive policies}

None of the universities in the study had established relevant open access supportive policies. Policies are considered important not only for motivating the researchers to publish in open access systems (Swan and Brown 2005), but also as a means of clarifying the objectives, processes and procedures relating to the open access activities. Many researchers publish in traditional journals, especially those that are already listed as university-recognised publications. Since researchers' rewards, and concomitantly their career development, usually depend on publishing in such select journals, deliberate policies to promote open access publishing would do the same. Unless deliberate incentives and supportive policies are enforced to promote open access publishing, it is unlikely that this publishing mode will flourish and outstrip the already well established traditional scholarly communication media (Fullard 2007; Hedlund and Montenen 2008).

\section{Conclusion and recommendations}

It is clear from the findings of this study that most researchers in Tanzanian public universities were aware of and positive towards the open access concept. However, the majority used open access outlets to access rather than publish their scholarly output, mainly because of skills inadequacy, the lack of supportive policies and researchers' fears.

For as long as most universities recognise only the traditional publications, for example refereed journals, as acceptable accredited output and since there is a perception that open access outputs are of lower quality because they do not undergo rigorous quality control, uptake of open access usage would remain poor. Additionally, the uncertainty about long-term availability of open access sites, the fear of exposure to plagiarism and loss of ownership, the poor ICT infrastructure and inadequate ICT skills are important barriers.

It became apparent that many researchers would welcome the establishment of institutional repositories as a way to improve dissemination of research output, especially conference papers, research reports, theses, dissertations and peer-reviewed articles 
emanating from their respective universities. However, it is very important that this content be reviewed, preferably within the academic unit, department or faculty, before being accepted or deposited in institutional repositories.

The university library is the most preferred unit within the university to manage the institutional repository. Self-archiving and publishing in online journals would be supplementary methods of disseminating research output, if researchers could become competent ICT users for these purposes.

Based on the above findings, the study recommends that universities and other research organisations in Tanzania and other developing countries establish institutional repositories to increase both research output dissemination and improved knowledge sharing. Not only would the research profile of these universities and their researchers be elevated, but more use and trust of open access outlets would also result. The future development of open access seems to be more promising for open access repositories than open access journals, perhaps because of the control factor. At the time of this study (2009), for example, there were only 3940 open access journals, which can publish only a limited number of articles. On the other hand, there are more than 2,5 million articles published annually in peer reviewed journals and other publications such as conference proceedings worldwide, which can be archived in open access repositories (Bjork et al. 2009; Harnad 2006; Regazzi and Caliguiri 2006). Self-archiving to a large extend depends on the ownership or availability of technological facilities, which are often lacking among individual researchers but are more readily available within universities or organisations. More importantly, institutional repositories in developing countries will have the opportunity to publish their own content without having to bow to the stringent requirements and competition often characteristic of commercial journal publishers and vendors. As long as reasonable and standard quality assurance measures are adopted, this option will ultimately improve the dissemination of institutional research output within and beyond country borders and probably greatly change the view that little or no scholarly content emanates from developing countries.

\section{Acknowledgement}

The authors would like to acknowledge the role of the Research on Poverty Alleviation (REPOA), a Non Governmental Organisation (NGO) based in Dar es Salaam, Tanzania for funding the data collection for this study. The authors are also indebted to all research assistants as well as the respondents for enabling this study. 


\section{References}

ALA (American Library Association). 2003. Principles and strategies for the reform of scholarly communication. [Online]. Available WWW: http://www.ala.org/acrl/acrclpubs/whitepapers/principlesstrategies.html (Accessed 7 July 2007).

Alemu, G.A. 2009. The role of open access in fostering knowledge sharing and collaboration in Ethiopia. A case study. [Online]. Available WWW: http://blogs.myspace.com/index.cfm (Accessed 15 October 2009).

Bailey, C.W. 2006. What is open access? [Online]. Available WWW: http://www.digital-scholarship.com/cwb/whatlsOA.htm (Accessed 8 August 2007).

Berlin Declaration of Open Access. 2003. [Online]. Available WWW: http://www.zim.mfg.de/openaccessberlin/berlin declaration.html (Accessed 24 July 2007).

Bernius, S., Hanauske, M., Konig, W. and Dugall, F. 2009. Open access models and their implications for the players on the scientific publishing market. Economic analysis \& policy 39 (1):103-115. [Online]. Available WWW: http://www.eapjournal.com.au/download.php?file=694 (Accessed 3 February 2010).

Bjork, B.C. 2004. Open access to scientific publications - an analysis of the barriers to change. Information Research 9(2). [Online]. Available WWW: http://InformationR.net/ir/9-2/paper170.html (Accessed 2 September 2006).

Bjork, B.C., Roos, A. and Lauri, M. 2009. Scientific journal publishing: yearly volume and open access availability. Information research 14(1). [Online]. Available WWW: http://informationr.net/ir/14-1/paper391.html (Accessed 17 March 2009).

Budapest Open Access Initiative. 2002. [Online]. Available WWW: http://www.soros.org/openaccess/read.shtml (Accessed 21 October 2006).

Chan, L. 2004. Supporting and enhancing scholarship in the digital age: the role of open access institutional repositories. Canadian journal of communication 29:277-300. [Online]. Available WWW: http://eprints.rclis.org/archive/00002590 (Accessed 22 November 2006).

Chan, L. and Costa, S. 2005. Participation in the global knowledge commons: challenges and opportunities for research dissemination in developing countries, New Library World 106 (1210/1211):141-163

Chege, K. 2006. Scientists get free access to environmental journals. [Online]. Available WWW: http://www.scidev.net/news/index.cfm (Accessed 2 November 2006).

Comba, V. and Vignocchi, M. 2005. Scholarly communication and open access: research communities and their publishing patterns (New trends in scholarly communication: how do authors of different research communities consider OA). [Online]. Available WWW: http://eprints.rclis.org/archive/00005779/ (Accessed 14 October 2006).

De Beer, J.A. 2005. Open access scholarly communication in South Africa: a role of national policy in the national system of innovation. Unpublished MPhil thesis, University of Stellenbosch. [Online]. Available WWW: http://www.jenniferdebeer.net/research/DeBeerJenniferThesisMPhil2004.pdf (Accessed 20 September 2006).

Deoghuria, S. and Roy, S. 2007. Open access: what scientists think? A survey of researchers' attitude towards open access. ICSD2007. [Online]. Available WWW: http://drtc.isibang.ac.in/bitstream/1849/314/1/081 P32 swapan deoghuria formatted.pdf (Accessed 4 August 2007).

Directory of Open Access Journals (DOAJ). 2009. [Online]. Available WWW: http://www.doaj.org (Accessed 24 July 2009). Directory of Open Access Journals (DOAJ). 2010. [Online]. Available WWW: http://www.doaj.org (Accessed 4 February 2010). Directory of Open Access Repositories (DOAR). 2009. [Online]. Available WWW: http://www.opendoar.org (Accessed 24 July 2009).

Directory of Open Access Repositories (DOAR). 2010. [Online]. Available WWW: http://www.opendoar.org (Accessed 4 February 2010).

Fang, C. and Zhu, X. 2006).The open access movement in China. Interlending and Document Supply 34 (4):186-193. 
Foster, N.F. and Gibbons, S. 2005. Understanding faculty to improve content recruitment for institutional repositories. D-Lib Magazine 11(1). [Online]. Available WWW: http://dlib.org/dlib/january05/01foster.html (Accessed 29 January 2007).

Fullard, A. 2007. South African response to open access publishing: a survey of the research community. SA Jnl libs \& Info Sci 73(1). [Online]. Available WWW: http://eprints.rclis.org/archive/00010749/01/SAJLIS 73(1)04.pdf (Accessed 10 July 2007).

Gadd, E., Oppenheim, C. and Probet, S. 2003. RoMEO studies 3 - how academics expect to use open access research papers. [Online]. Available WWW: http://eprints.rclis.org/archive/00001427/ (Accessed 12 October 2006).

Habib, A. 2009. South Africa: huge journal profits hit universities. [Online]. Available WWW: http://www.universityworldnews.com/article.php? (Accessed 30 November 2009).

Harle, J. 2009. Digital resources for research: a review of access and use in African universities. An issue paper prepared as part of an ACU study for Arcadia. Available: http://www.scidev.net/en/news/African-universities-face-fresh-internet-challenge.html (Accessed 25 August 2009).

Harnad, S. 2006. Maximising research impact through institutional and national open access self-archiving mandates. [Online]. Available WWW: http://cogprints.org/4787/02/harnad.crisrev.pdf (Accessed 27 January 2007).

Hedlund, T. and Montenen, C. 2008. Promoting open access in Finland - the OA-JES project. Sciecom info 1(2008):1-3. [Online]. Available WWW: http://www.sciecom.org/ojs/index.php/sciecominfo/article/view/242/91 (Accessed 4 February 2010).

Hess, T., Wigang, R.T., Mann, F. and Walter, B.V. 2007. Open access and science publishing: results of a study on researchers' acceptance and use of open access publishing. Management report 1/2007. [Online]. Available WWW: http://openaccessstudy.com/Hess Wigang mann Wlter 2007 Open Access management Report.pdf (Accessed 24 March 2007).

Hirwade, M. and Rajyalakshmi, D. 2006. Open access: India is moving towards third world super power. [Online]. Available WWW: http://eprints.rclis.org/archive/00006798/01/99107D29.pdf (Accessed 14 October 2006).

Kim, J. 2006. Motivating and impeding factors affecting faculty contribution to institutional repositories. [Online]. Available WWW: http://sils.unc.edu/events/2006jcdl/digitalcuration/kim-JCDLworkshop2006.pdf (Accessed 30 January 2007).

Kirsop, B. and Chan, L. 2005. Transforming access to research literature for developing countries. Serials review, 31 (4): $246-255$.

Lwoga, E. 2006. Agricultural research online system: an approach to promote collaboration and sharing of agricultural research knowledge in Tanzania. (M.Sc. dissertation). University of Dar es Salaam. [Unpublished].

Lynch, C. 2003. Check out the new library. Ubiquity 4(23). [Online]. Available WWW:

http://www.acm.org/ubuiquity/interviews/pf/clynch1.html (Accessed 16 January 2006).

Mann, F., Walter, B., Hess, T. and Wigand, R.F. 2008. Open access publishing in science: why it is highly appreciated but rarely used. [Online]. Available WWW: http://openaccess-study.com/Mann et al 2008 Open Access Publishing in Science.pdf (Accessed 5 August 2009).

Moller, A.M. 2006. The case of open access publishing, with special reference to open access journals and their prospects in South Africa. (M.A. dissertation). University of the Western Cape. [Unpublished]. [Online]. Available WWW: http://eprints.rclis.org/archive/000518/01/MollerThesis.pd (Accessed 2 September 2006).

Neuman, W.L. 2007. Basics of social research: qualitative and quantitative approaches. $2^{\text {nd }}$ ed. Boston: Pearson Education, Inc.

Papin-Ramchan, J.I. and Dawe, R.A. 2006. Open access publishing: a developing country view. First Monday 11 (6). [Online]. Available WWW: http://firstmonday.org/issues/issue11-6/papin/index.html (Accessed 1 September 2006).

Pelizzari, E. 2003. Academic staff use, perception and expectations about open-access archives: a survey of social science sector at Brescia University. [Online]. Available WWW: http://prints.rclis.org/archive/00000737/01/Academic staff-perception abot arch (Accessed10 October 2006).

Pickton, M.J. 2005. Research students and the Loughborough institutional repository. (Masters dissertation). UK: University of Loughborough. [Unpublished]. [Online]. Available WWW:

http://dspace.lboro.ac.uk/dspace/bitstream/2134/571/1/Miggie dissertation.pdf (Accessed15 July 2006). 
Regazzi, J.J. and Caliguiri, N.A. 2006. Publisher and author partnerships: a changing landscape. Learned publishing 19(3):183192.

SARUA (Southern African Regional Universities Association). 2008. Open access to knowledge in Southern African Universities. Study series 2008. Compiled by Luci Abrahams and team. [Online]. Available WWW: http://www.sarua.org/files/publications/ST (Accessed 24 April 2009).

Schroter, S. and Tite, L. 2006. Open access publishing and author-pays business models: a survey of authors' knowledge and perceptions. Journal of the Royal Society of Medicine 99. [Online]. Available WWW: http://www.jrsm.org/cgi/content/full/99/3/141 (Accessed 8 August 2006).

Shame, Z. 2009. JK: new telecom era here. The Guardian Friday 24 July, Issue no. 4573.

Swan, A. 2007. Open access and progress of science. The American Scientist Online. [Online]. Available WWW: http://www.americanscientist.org/template/asstdetail/55131 (Accessed 15 July 2007).

Swan, A. and Brown, S. 2004. JISC/OSI journal authors survey report, key prospects, Truro. [Online]. Available WWW: http://www.jisc.ac.uk/uploaded documents/JISCOAreport1.pdf (Accessed 24 September 2006).

Swan, A. and Brown, S. 2005. Open access self-archiving: an author survey. [Online]. Available WWW: http://eprints.ecs.soton.ac.uk/10999/ (Accessed 29 January 2007).

Thorin, S.E. 2003. Global changes in scholarly communication. [Online]. Available WWW: http://www.arl.org/bm doc/thorin.pdf (Accessed 3 February 2010).

Van der Merwe, A. and Kroeze, J.H. 2008. Development and implementation of an institutional repository within a science, engineering and technology (SET) environment. [Online]. Available WWW:

http://researchspace.csir.co.za/dspace/bitstream/10204/2500/1/van\%20Merwe1 208.pdf (Accessed 19 February 2009).

Wang, X. and Su, C. 2006. Open access - philosophy, policy and practice: a comparative study. In: Proceedings of the World Library and Information Congress: $72^{\text {nd }}$ IFLA general conference and council 20-24 August 2006, Seoul, Korea. [Online]. Available WWW: http://elpub.scix.net/data/workshop/att/121-elpub2007.content.pdf (Accessed 19 February 2009).

Ware, L. 2004. Institutional repositories and scholarly publishing. Learned Publishing 17(2):115-124.

Warlick, S.E. and Voughan, K.T. 2006. Factor influencing publication choice: why faculty choose open access. Biomedical digital libraries 4(1). [Online]. Available WWW: http://www.pubmedcentral.nih.gov/picrender.fcgi?article=1832218blobtype=pdf (Accessed 4 August 2007).

Willinsky, J. 2003. The nine flavours of open access scholarly publishing. Journal of Postgraduate Medicine 49:263-267. [Online]. Available WWW: http://www.jpgmonline.com/text.asp?2003/49/3/263/1146 (Accessed 25 July 2007).

Xu, H. 2005. Faculty's attitude to institutional repositories and factors affecting the attitude. [Online]. Available WWW: http://meta.lis.edu/starchive/handle/2189/71 (Accessed 29 January 2007).

Yiotis, K. 2005. The open access initiative: a new paradigm for scholarly communications. Information technology and libraries 24(4):157-162. 